\title{
Konsep Green Building Masjid Baiturahman SMAN 3 Kuningan
}

Atik Rosanti', Abdul Raup ${ }^{2}$, Kardi Leo ${ }^{3}$, Muhibbin Syah ${ }^{4}$, Muhammad Erihadiana ${ }^{5}$

1,2,3,4,5Universitas Islam Negeri Sunan Gunung Djati Bandung, Indonesia

E-mail: atikrosanti96@gmail.com, abdulraup.pascauin@gmail.com, kardileo84@gmail.com,

muhibbinsyah@yahoo.com, erihadiana@uinsgd.ac.id

\begin{tabular}{l}
\hline Article Info \\
\hline Article History \\
Received: $2021-11-02$ \\
Revised: $2021-11-22$ \\
Published: $2021-12-04$
\end{tabular}

Keywords: Green Building; Mosque; SMAN 3 Kuningan.

\begin{abstract}
Green Building is a building that applies environmental principles in its design, construction, operation and processing and important aspects of handling the impacts of climate change. The mosque was built to function not only as a place of worship but also aims to unite spiritual ideals while upholding the ideals social development in the development of a civilized society, becomes a means and strength in efforts to develop and inculcate good values and renewal of people's lives. This study aims to find out information related to the implementation of Green Building and the obstacles in implementing Green Building at SMAN 3 Kuningan. The research method used in this study is a qualitative method. The results of this study indicate that at SMAN 3 Kuningan the implementation of Green Building at the Biturahman Mosque at SMAN 3 Kuningan is 1). Baiturrahman Mosque SMAN 3 Kuningan has succeeded in carrying out the concept of Green building as an effort to reduce global warming and energy efficiency. 2). The obstacles faced are related to consistency, and contribution in carrying out green building.
\end{abstract}

\begin{tabular}{l}
\hline Artikel Info \\
\hline Sejarah Artikel \\
Diterima: $2021-11-02$ \\
Direvisi: $2021-11-22$ \\
Dipublikasi: $2021-12-04$
\end{tabular}

Kata kunci:

Green Building; Masjid;

SMAN 3 Kuningan.

\section{PENDAHULUAN}

Kerusakan lingkungan tanpa disadari kini telah menjadi fokus penting di seluruh Negara. Pemanasan gelobal menjadi topik hangat yang muncul akhir-akhir ini akhibat permasalahan lingkungan dikarenakan aktivitas kebutuhan manusia yang terus bertambah (Tanjung, 2020). Eksploitasi sumber daya alam yang berlebih mengakibatkan merosotnya kualitas alam (Sucipto, 2017). Hal tersebut tentu saja berdampak bagi manusia karena pemanasan global akan sangat merugikan. Pemanasan global terjadi dikarenakan kebutuhan dan aktivitas manusia terus bertambah akibatnya hal tersebut menimbulkan beberapa dampak diantaranya adalah penipisan lapisan ozon, perubahan iklim dan meningkatnya suhu bumi. Beberapa hal yang dapat memicu pemanasan global, salah satunya adalah penyempitan lahan terbuka hijau, efek rumah kaca, dan pembangunan yang tidak memperhatikan lingkungan (Roshaunda, 2019), salah satunya terdapat istilah Sick Building Syndrome (SBS) dalam dunia arsitektur yang merupakan masalah yang cukup penting untuk diperhatikan akibat pemanasan global (Camelia, 2011), gejalanya hanya dirasakan oleh seseorang yang beraktifitas didalam ruangan atau bangunan. Gejalanya tidak terlalu terlihat secara spesifik namun terdapat penurunan kesehatan karena buruknya kualitas udara (Mawarni, 2021). Indikasi buruknya kualitas udara dalam ruangan diakibatkan oleh beberapa hal 
diantaranya adalah suhu ruangan yang kurang baik, pencahayaan yang minim, karbon dioksida, ventilasi yang kurang mendukung, PM 2.5, kelembaban ruangan yang buruk akibat kurangnya sinar matahari yang masuk kedalam ruangan (Rahmawati, 2020), dan kondisi lingkungan yang sudah kehilangan ruang-ruang terbuka hijau yang menyumbang udara segar keberadaannya sudah sangat terbatas (Rahmy, 2012).

Berbagai dampak yang terjadi merupakan sebuah risiko, menurut (Arifudin, 2020) bahwa risiko merupakan konsekuensi dari semua perilaku yang telah dilakukan. Selain itu, pencemaran dan tercemarnya air sangat merugikan masyarakat dan lingkungan sekitar menurunkan kualitas kesehatan masyarakat (Puspitasari, 2009) akibat hilangnya dan minimnya pemanfaatan air limbah, salah satunya limbah air wudhu. Untuk itu, maka muncul adanya penciptaan atau inovasi energi yang terbarukan yang melatar belakangi lahirnya konsep Gedung Hemat Energi atau lebih dikenal dengan sebutan Green Building dalam dunia arsitektur.

Green Building adalah suatu bangunan yang menerapkan prinsip lingkungan dalam perancangan, pembangunan, pengoprasian dan pengolahannya dan aspek penting penanganan dampak perubahan iklim (Bria, 2017). Konsep ini terus digencarkan pembangunannya sebagai salah satu ikhtiar antisipasi perubahan iklim gelobal. "Dengan konsep hemat energi yang tepat, konsumsi suatu gedung dapat diturunkan hingga $50 \%$, dengan hanya menambah $5 \%$ dari biaya pembangunan gedung biasa, konsumsi energi gedung dapat diturunkan hingga 50\%." Green Building dibangun dengan perencanaan efesiensi energi secara modern. Selain dari sisi design bangunan yang dirancang guna memudahkan masuknya sinar matahari sebagai pencahayaan alami, perancangan green building juga mampu meminimalisir penggunaan lampu listrik dan memudahkan keluar masuknya udara dari ventilasi yang terbuka sebagai pengganti beban Air Condition (AC). Untuk itu konsep green building cocok digunakan untuk menangani perubahan iklim yang saat ini semakin menghawatirkan.

Masjid dibangun berfungsi tidak hanya sebagai tempat ibadah semata akan tetapi juga bertujuan untuk menyatukan cita-cita spiritual dengan tetap menjunjung cita-cita sosialnya dalam pembangunan masyarakat yang madani, menjadi sarana serta kekuatan dalam upaya pembangunan dan penanaman nilai-nilai kebaikan dan pembaharuan kehidupan umat (Prabowo, 2019). Selanjutnya, keberadaan sekolah sebagai lembaga formal sesuai Peraturan Menteri Pendidikan Nasional RI Nomor 24 Tahun 2007 tentang Standar Sarana dan Prasarana untuk SD/MI, SMP/MTs, dan SMA/MA. Pada peraturan tersebut, sekolah di semua jenjang diwajibkan memiliki tempat ibadah, seperti masjid (Najib, 2014). Oleh karenanya penerapan Green Building pada perencanaan, perancangan, pembangunan serta pemeliharaan masjid dirasa tepat untuk menjawab permasalahan yang ada saat ini. Diharapkan mampu mendorong dan membentuk jamaah serta masyarakat dalam pemuiaan lingkungan (Prabowo, 2019).

Beberapa penelitian terdahulu telah melakukan penelitian terkait green building diantaranya penelitian yang dilakukan oleh Diza Roshaunda $\mathrm{dkk}$, dengan artikel yang berjudul "Penilaian Kriteria Green Building pada Bangunan Gedung Universitas Pembangunan Jaya Berdasarkan Indikasi Green Building Council Indonesia". Berkesimpulan bahwa penerapan green building pada konsep suatu bangunan dapat menjadi solusi pemanasan gelobal yang bersumber dari aktivitas manusia terkait pembangunan yang terus-menerus bertambah (Roshaunda, 2019). Selanjutnya Nurhidayat Muh. Said berkesimpulan dalam artikelnya yang berjudul "Manajemen Masjid: Studi Pengelolaan Masjid Agung Al-Azhar Jakarta" bahwa masjid di kelola dengan perencanaan baik. Tidak hanya sebagai tempat peribadatan umat islam namun juga sebagai tempat penyelesaian permasalahan masyarakat (Said, 2016).

\section{METODE PENELITIAN}

Penelitian ini menggunakan pendekatan kualitatif, tujuan dalam penelitian adalah untuk mendapatkan gambaran Konsep green building di Masjid Baiturahman SMA 3 Kuningan. Menurut (Rahayu, 2020) mengemukakan bahwa penelitian kualitatif merupakan penelitian yang mencari gambaran secara mendalam terkait sebuah fenomena yang terjadi, satu-satunya unsur perlakuan yang diberikan dalam penelitian ini hanyalah penelitian itu sendiri yang dilakukan melalui wawancara, observasi pengedaran angket atau dokumentasi. Langkah-langkah penelitian ini meliputi: tahap persiapan, diagnostik, perencanaan, pelaksanaan, evaluasi, dan hasil, adapun Subjek dalam penelitian ini adalah pengurus Masjid Baiturahman SMA 3 Kuningan, penelitian ini dilaksanakan pada bulan September-Oktober 2021. 
1. Teknik Pengumpulan Data

Teknik pengumpulan data yang digunakan dalam penelitian adalah tes dan Oservasi.

a) Wawancara

Pengumpulan data dengan wawancara metode SWOT (strength/kekuatan, weakness /kelemahan, opportunity/ peluang, treats/hambatan) kepada pengurus Masjid Baiturahman SMA 3 Kuningan. Wawancara dengan list pertanyaan open-ended ditanyakan pada narasumber. Wawancara menurut (Bahri, 2021) mengemukakan bahwa teknik mengumpulkan informasi dengan cara mengkonfirmasi narasumber yang terkait dengan tema penelitian.

b) Observasi

Observasi digunakan untuk menjawab permasalahan yang diajukan dalam penelitian ini. Lembar observasi digunakan untuk mengamati konsep green building Masjid Baiturahman SMA 3 Kuningan dilaksanakan oleh pengamatan (Observer). Menurut Sugiyono dalam (Tanjung, 2021) menjelaskan bahwa, observasi merupakan dasar dari semua ilmu pengetahuan. Teknik observasi yang digunakan dalam penelitian ini menggunakan Teknik "semi terstruktur" yang memberikan ruang gerak bagi peneliti untuk mengubah fokus dari satu kejadian ke kejadian lain seiring dengan munculnya kejadian-kejadian baru yang mungkin lebih memiliki daya tarik dan menjadi penyebab munculnya kejadian ke kejadian lain.

\section{Alat Pengumpulan Data}

Alat pengumpulan data yang digunakan dalam penelitian ini ada dua, yaitu lembar wawancara dan lembar panduan observasi.

a. Lembar wawancara

Lembar wawancara digunakan untuk menjaring persepsi para subyek penelitian.

b. Lembar Panduan Observasi

Instrumen ini dirancang peneliti untuk mengumpulkan data mengenai kinerja guru dan aktivitas belajar siswa selama penelitian.

\section{Teknik Analisis Data}

Penelitian ini dianalisis dengan menggunakan analisis data kualitatif. Menurut (Sofyan, 2020) bahwa analisis kualitatif, digunakan untuk menganalisis data hasil wawancara dan observasi yang menunjukkan proses yang memberikan pemaknaan secara kontekstual dan mendalam sesuai dengan permasalahan penelitian yaitu tentang konsep green building.

4. Prosedur Penelitian

Langkah-langkah penelitian disusun dan dikembangkan secara sistematis untuk mempermudah proses pelaksanaan penelitian. Adapun menurut (Nasser, 2021) bahwa prosedur penelitian ini sebagai berikut:

a. Tahap Persiapan

Pada tahap persiapan, peneliti memilih masalah penelitian dengan melakukan studi kepustakaan yang berasal dari beberapa rujukan seperti buku, disertasi, jurnal dan lain-lain, selanjutnya melakukan studi ke lokasi penelitian sebagai pendahuluan, dengan melakukan diskusi dengan pengurus Masjid Baiturrahman SMAN 3 Kuningan. Melalui serangkaian diskusi kelompok, kemudian memilih pendekatan yang akan digunakan yaitu pendekatan penelitian kualitatif metode deskriptif analitik serta menentukan lokasi dan subjek penelitian, dengan lokasi Penelitian yaitu Masjid Baiturrahman SMAN 3 Kuningan. Sumber data didapatkan dari hasil pengumpulan data dari wawancara, observasi dan kuesioner, penentuan dan penyusunan instrumen yang akan digunakan dalam kegiatan penelitian, dilakukan atas kerja sama kelompok dengan dilakukan analisis untuk menentukan validitas dan reliabilitas instrumen.

b. Tahap Pelaksanaan

Pada tahap pelaksanaan, peneliti secara langsung terlibat dalam kegiatan di Masjid Baiturrahman SMAN 3 Kuningan dengan melakukan observasi, wawancara dengan kepala pengurus Masjid Baiturrahman SMAN 3 Kuningan.

c. Tahap Pengolahan Data

Kegiatan yang dilaksanakan dalam tahap ini adalah Pengolahan dan penganalisisan data hasil penelitian berupa hasil wawancara, observasi dan kuesioner, kemudian penarikan kesimpulan dari hasil olah data dan analisis data penelitian.

d. Tahap Penyusunan Laporan

Penulisan laporan dalam bentuk tulisan disesuaikan dengan ketentuan penulisan karya tulis ilmiah.

\section{HASIL DAN PEMBAHASAN}

Masjid Bairurahman SMA 3 Kuningan mengusung konsep Green Bilding yang 
merupakan masjid ramah lingkungan pertama di Kabupaten Kuningan. Tujuannya tidak lain untuk menciptakan masjid yang memperhatikan lingkungan dan efisiensi energi. Hal tersebut sesuai dengan Firman Allah " Hanya yang memakmurkan masjid-masjid Allah ialah orangorang yang beriman kepada Allah dan hari kemudian, serta tetap shalat, menunaikan zakat, dan tidak takut pada siapapun selain pada Allah maka merekalah orang-orang yang diharapkan termasuk orang-orang yang mendapat petunjuk".

1. Perencanaan Penerapan Green Building

a) Efesiensi Energi

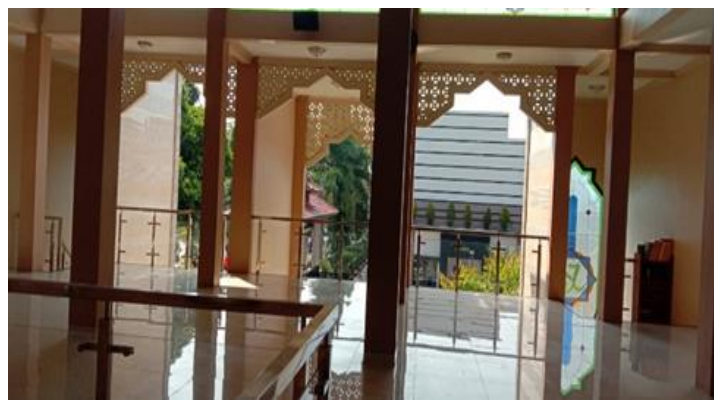

Masjid Baiturrahman SMAN 3 Kuningan merupakan masjid pertama di Kabupaten Kuningan yang menerapkan konsep masjid ramah lingkungan, nilai-nilai konservasi, pelesrarian lingkungan dan mengurangi ketergantungan energi. Tanpa adanya jendela memudahkan sinar matahari masuk dan udara dengan bebas keluar-masuk ruangan hingga mampu meniadakan penggunaan AC/Kipas Angin dan meminimalisir aktivitas penggunaan listrik (Rauf, 2021).

b) Efesiensi Air

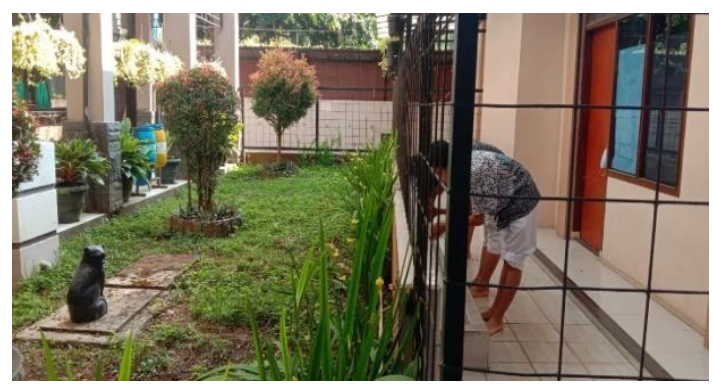

Bangunan Masjid Bairurahman SMAN 3 Kuningan sudah mampu mengendalikan efesiensi air. Hal tersebut dikarenakan SMAN 3 Kuningan telah memiliki embung penyimpanan air yang khusus untuk dipergunakan oleh jamaah masjid. Selain itu, bekas air wudhu mengalir ke bak penampungan yang selanjutnya dialirkan ke beberapa kolam ikan dan digunakan untuk penyiraman tanaman yang berada di SMAN 3 Kuningan. Hal ini sudah sesuai dengan ketentuan konversi air yang mencangkup terkait penggunaan sumberdaya air, daur ulang air dan perbaikan keseimbangan air (Rinka, 2014) dan pemanfaatan air bekas wudu yang di alirkan ke dalam kolam ikan dan digunakan sebagai penyiraman pohonpohon serta bunga-bunga di sekolah sebagai upaya pemanfaatan limbah air wudu agar tidak terbuang percuma (Mawangi, 2020).

c) Efesiensi Bahan/ Matrial

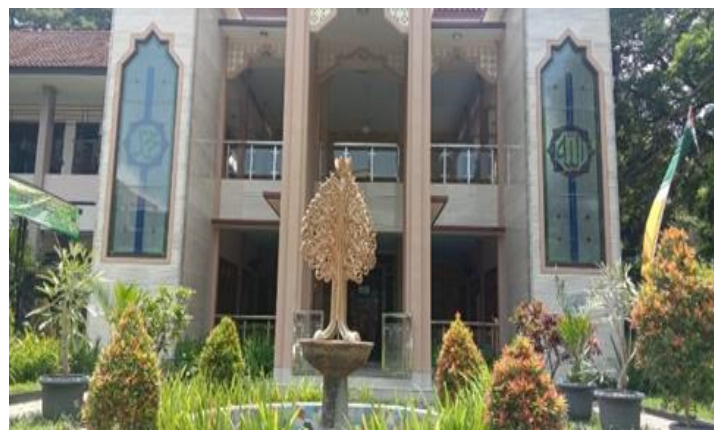

Bahan yang digunakan oleh Masjid Baiturahman SMAN 3 Kuningan masih belum mengusung material ramah lingkungan. Bahan baku pembangunan masjid masih menggunakan batu bata, pasir, semen dan lainnya yang belum menggunakan bahan daur ulang.

d) Peningkatan Mutu Lingkungan

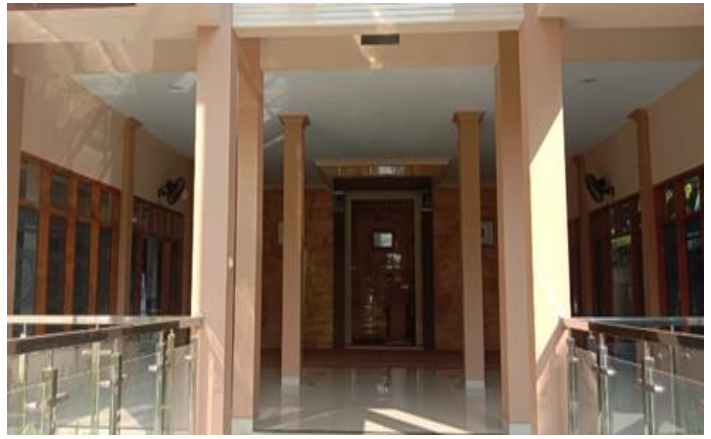

Masjid Baiturrahman SMAN 3 Kuningan secara konsisten menjalankan mutu lingkungan dengan menata penghijauan, terdapat bio pori, mengolah sampah menjadi hal yang berguna, menggunakan bekas air wudhu menjadi hal yang bermanfaat, dan tidak menggunakan AC sebagai pendingin ruangan yang tentu akan menyumbang pemanasan gelobal (Prabowo, 2019). 
e) Operasi dan Optimalisasi Pemeliharaan

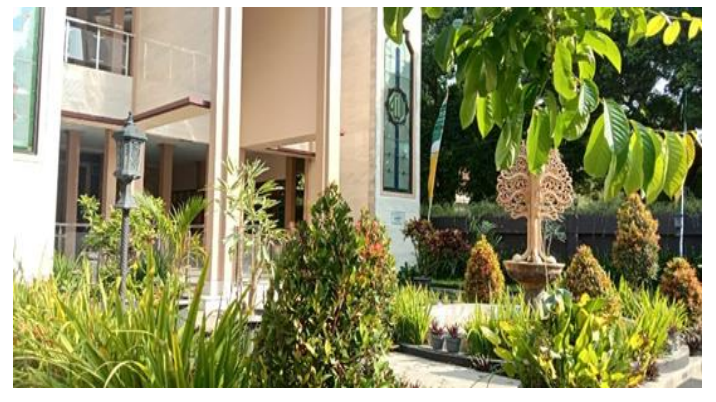

Pemeliharaan bangunan sudah sangat baik. Air untuk wudhu jamaah tercukupi, tanaman tertata sangat sehat dan asri, tempat peribadatan bersih dan rapi. Hal ini sebagai respon terhadap kebutuhan ruang terbuka hijau (Rahmy, 2012).

f) Pengurangan Sampah

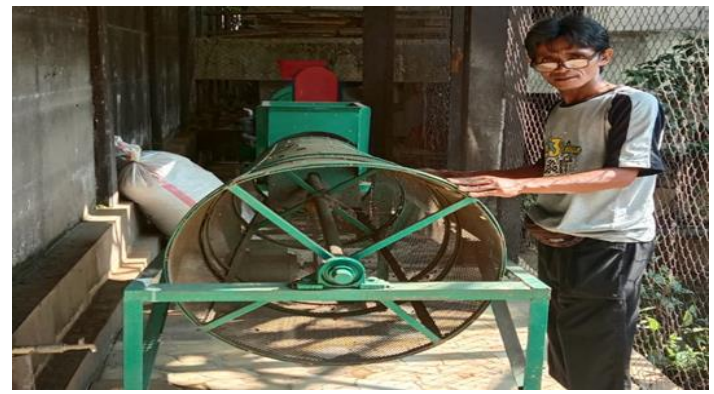

Dalam penanganan sampah, masjid SMAN 3 Kuningan memiliki cara tersendiri dengan membagi 3 kelopok sampah. Pertama, sampah organik di kelola menjadi pupuk organik. Kedua, sampah anorganik dipilah sesuai kebutuhan. Sampah yang dapat di jual dikumpulkan kemudian di jual. Sampah yang tidak dapat dijual di kumpulkan dan di berikan kepada dinas kebersihan. Hal tersebut akan membantu permasalahan lingkungan, menyumbang pendapatan kas masjid dan membantu kenyamanan lingkungan (Maulana, 2020).

g) Optimalisasi Biaya dan Manfaat

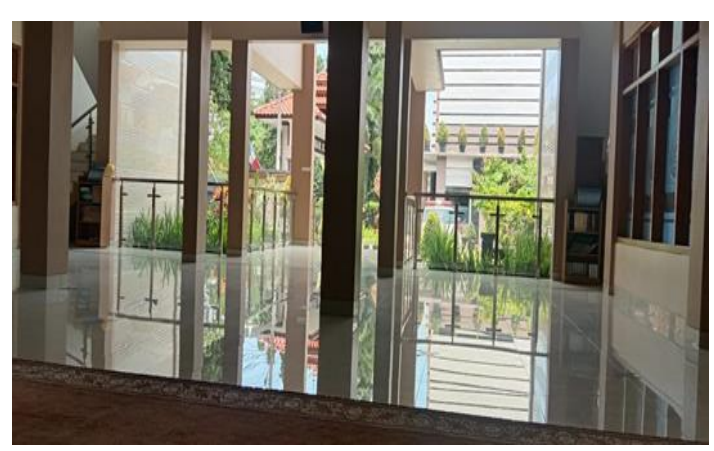

Masjid Baiturrahman SMAN 3 Kuningan sangat efesien terhadap biaya. Pemanfaatan limbah air wudhu untuk pengisian air kolam ikan dan pemanfaatannya auntuk penyiraman bunga dan pohon di sekitaran masjid dan sekolah, serta konsep masjid tanpa jendela yang membantu meniadakan penggunaan kipas angin dan AC (Maulana, 2020). Semua itu tentu mengurangi pengeluaran dan penggunaan listrik untuk pencahayaan dan pendingin.

h) Peraturan dan Operasi

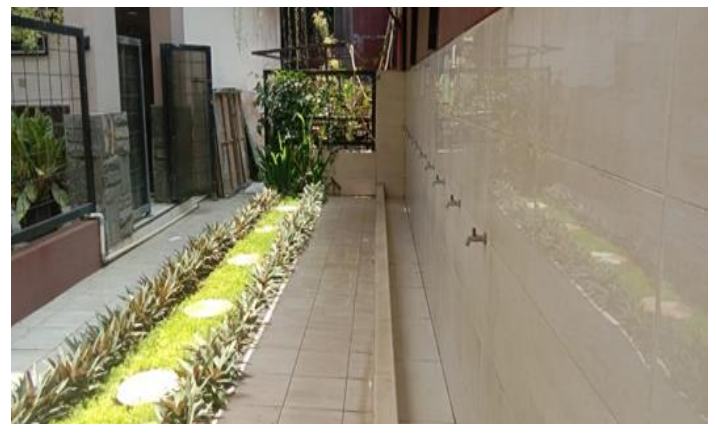

Hal yang unik dari masjid ini adalah hampir tanpa stiker peringatan/ peraturan, karena peraturan tersebut sudah masuk ke dalam muatan pembelajaran.

2. Hambatan-hambatan penerapan green building pada masjid Baiturrahman SMAN 3 Kuningan, diantaranya:

a) Komitmen Tinggi. Ketidak kompakan antara pengurus terkadang menjadi hambatan dalam pelaksanaan konsep green building di masjid Baiturrahman SMAN 3 Kuningan.

b) Kontribusi Pengurus. Kesibukan antar pengurus terkadang menjadi hambatan tersendiri dalam pelaksanaan kegiatan.

c) Konsistensi. Ketidak sama ratanya pemahaman konsep green building terkadang menjadi hambatan tersendiri diantara pengurus dan jamaah.

\section{SIMPULAN DAN SARAN}

\section{A. Simpulan}

Penerapan Green Building pada Masjid Baiturahman SMAN 3 Kuningan adalah:

a) Efesiensi Energi. Masjid tanpa jendela memudahkan sinar matahari untuk masuk dan udara dengan bebas keluar-masuk ruangan hingga mampu meniadakan penggunaan AC/Kipas Angin dan meminimalisir aktivitas penggunaan listrik.

b) Efesiensi Air. Mampu mengendalikan efesiensi air, hal tersebut dikarenakan telah memiliki embung penyimpanan air yang khusus untuk dipergunakan oleh 
jamaah masjid. Selain itu, bekas air wudhu mengalir ke bak penampungan yang selanjutnya dialirkan ke beberapa kolam ikan dan digunakan untuk penyiraman tanaman yang berada di SMAN 3 Kuningan. Hal ini sudah sesuai dengan ketentuan konversi air yang mencangkup terkait penggunaan sumberdaya air, daur ulang air dan perbaikan keseimbangan air.

c) Efesiensi Bahan/ Matrial. Bahan bangunan yang digunakan masih belum mengusung material ramah lingkungan. Bahan baku pembangunan masjid masih menggunakan batu bata, pasir, semen dan lainnya yang belum menggunakan bahan daur ulang.

d) Peningkatan Mutu Lingkungan. Secara konsisten menjalankan mutu lingkungan dengan menata penghijauan, terdapat bio pori, mengolah sampah menjadi hal yang berguna, menggunakan bekas air wudhu menjadi hal yang bermanfaat, dan tidak menggunakan AC sebagai pendingin ruangan yang tentu akan menyumbang pemanasan gelobal.

e) Operasi dan Optimalisasi Pemeliharaan. Pemeliharaan bangunan sudah sangat baik. Air untuk wudhu jamaah tercukupi, tanaman tertata sangat sehat dan asri, tempat peribadatan bersih dan rapi. Hal ini sebagai respon terhadap kebutuhan ruang terbuka hijau.

f) Pengurangan Sampah. Dalam penanganan sampah, masjid SMAN 3 Kuningan memiliki cara tersendiri dengan membagi 3 kelopok sampah. Pertama, sampah organik di kelola menjadi pupuk organik. Kedua, sampah anorganik dipilah sesuai kebutuhan. Sampah yang dikumpulkan kemudian dapat dijual, Sampah yang tidak dapat dijual di kumpulkan dan di berikan kepada dinas kebersihan, hal tersebut akan membantu permasalahan lingkungan, menyumbang pendapatan kas masjid dan membantu kenyamanan lingkungan.

g) Optimalisasi Biaya dan Manfaat. Pemanfaatan limbah air wudhu untuk pengisian air kolam ikan dan pemanfaatannya auntuk penyiraman bunga dan pohon di sekitaran masjid dan sekolah, serta konsep masjid tanpa jendela yang membantu meniadakan penggunaan kipas angin dan AC sangat efesien terhadap biaya.

h) Peraturan dan Operasi. Hal yang unik dari masjid ini adalah hampir tanpa stiker peringatan/peraturan. Karena peraturan tersebut sudah masuk ke dalam muatan pembelajaran.

Hambatan-hambatan dalam penerapan Green Building pada Masjid Baiturahman SMAN 3 Kuningan adalah membutuhkan komitmen tinggi, kontribusi pengurus, serta konsistensi terkadang masih menjadi hambatan.

\section{B. Saran}

Berdasarkan hasil penelitian dan kesimpulan penulis menyarankan:

a) Agar penerapan green building Masjid Baiturrahman SMAN 3 Kuningan dapat dimaksimalkan pada bangunan yang mengusung bahan daur ulang. Agar lebih efisien dalam anggaran dan perawatan.

b) Hambatan yang dihadapi harus segera di selesaikan dengan mempererat kebersamaan antara satu sama lain pemangku kebijakan.

\section{DAFTAR RUJUKAN}

Arifudin, O. (2020). Manajemen Risiko. Bandung : Widina Bhakti Persada.

Bahri, A. S. (2021). Pengantar Penelitian Pendidikan (Sebuah Tinjauan Teori dan Praktis). Bandung : Widina Bhakti Persada.

Camelia. (2011). Sick Building Syndrome Dan Indoor Air Quality. Jurnal Ilmu Kesehatan Masyarakat, 2(2), 79-84.

Mawarni. (2021). Keluhan Sick Building Syndrome di Gedung PT. X. Jurnal Kesehatan Lingkungan Indonesia, 20(1), 39-46.

Najib. (2014). Manajemen Masjid Sekolah Sebagai Laboratorium Pendidikan Karakter Bagi Peserta Didik. Ta'dib:Journal of Islamic Education (Jurnal Pendidikan Islam), 19(1), 85-110.

Nasser, A. A. (2021). Sistem Penerimaan Siswa Baru Berbasis Web Dalam Meningkatkan Mutu Siswa Di Era Pandemi. Biormatika: Jurnal Ilmiah Fakultas Keguruan Dan Ilmu Pendidikan, 7(1), 100-109.

Prabowo. (2019). Ecomasjid Dari Masjid Makmurkan Bumi. Jakarta: OSF Preprints.

Puspitasari. (2009). Dampak Pencemaran Air Terhadap Kesehatan Lingkungan dalam 
Perspektif Hukum Lingkungan. Mimbar Hukum, 21(2), 23-34.

Rahayu, Y. N. (2020). Program Linier (Teori Dan Aplikasi). Bandung : Widina Bhakti Persada.

Rahmawati. (2020). Pengaruh kualitas udara dalam ruangan bagi performa akademik pelajar: sebuah tinjauan literatur. Jurnal Kesehatan Lingkungan Indonesia, 5(1), 3439.

Rahmy. (2012). Kebutuhan Ruang Terbuka Hijau Kota pada Kawasan. Lingkungan Binaan Indonesia, 1(1), 27-38.

Roshaunda. (2019). Penilaian Kriteria Green Building Pada Bangunan Gedung Universitas Pembangunan Jaya Berdasarkan Indikasi Green Building Council Indonesia. Widyakala Journal, 6(29), 15-25.

Said. (2016). Manajemen Masjid ( Studi Pengelolaan Masjid Agung Al-Azhar Jakarta ). Jurnal Tabligh, 3(1), 84-96.
Sofyan, Y. (2020). Peranan Konseling Dosen Wali Dalam Meningkatkan Motivasi Belajar Mahasiswa Di Perguruan Tinggi Swasta Wilayah LLDIKTI IV. Jurnal Bimbingan Dan Konseling Islam, 10(2), 237-242.

Sucipto. (2017). Kajian Penerapan Green Building Pada Gedung Bank Indonesia Surakarta. Jurnal Ilmiah Pendidikan Teknik Dan Kejuruan, 7(2), 17-24.

Tanjung, R. (2020). Manajemen Mitigasi Bencana. Bandung: Widina Bhakti Persada.

Tanjung, R. (2021). Kompetensi Manajerial Kepala Sekolah Dalam Meningkatkan Kinerja Guru Sekolah Dasar. JIIP-Jurnal Ilmiah Ilmu Pendidikan, 4(4), 291-296. https://doi.org/https://doi.org/10.54371/ jiip.v4i4.272 